Article

\title{
Knockdown of Butyrylcholinesterase but Not Inhibition by Chlorpyrifos Alters Early Differentiation Mechanisms in Human Neural Stem Cells
}

\author{
Angela K. Tiethof ${ }^{1}$, Jason R. Richardson ${ }^{1,2, *}$ and Ronald P. Hart ${ }^{3, *}$ (i) \\ 1 Joint Program in Toxicology, Environmental and Occupational Health Science Institute, Rutgers University, \\ Piscataway, NJ 08854, USA; angelatiethof@gmail.com \\ 2 Environmental Health Sciences, Robert Stempel School of Public Health and Social Work, \\ Florida International University, Miami, FL 33199, USA \\ 3 Department of Cell Biology \& Neuroscience and the Human Genetics Institute of New Jersey, Piscataway, \\ NJ 08854, USA \\ * Correspondence: jarichar@fiu.edu (J.R.R.); rhart@rutgers.edu (R.P.H.); \\ Tel.: +305-348-6742 (J.R.R.); +848-445-1783 (R.P.H.)
}

Received: 28 June 2018; Accepted: 29 August 2018; Published: 1 September 2018

\begin{abstract}
Butyrylcholinesterase (BChE) is the evolutionary counterpart to acetylcholinesterase (AChE). Both are expressed early in nervous system development prior to cholinergic synapse formation. The organophosphate pesticide chlorpyrifos (CPF) primarily exerts toxicity through the inhibition of AChE, which results in excess cholinergic stimulation at the synapse. We hypothesized that the inhibition of $\mathrm{AChE}$ and BChE by CPF may impair early neurogenesis in neural stem cells (NSCs). To model neurodevelopment in vitro, we used human NSCs derived from induced pluripotent stem cells (iPSCs) with a focus on the initial differentiation mechanisms. Over the six days of NSC differentiation, the BChE activity and mRNA expression significantly increased, while the AChE activity and expression remained unchanged. The CPF treatment $(10 \mu \mathrm{M})$ caused $82 \%$ and $92 \%$ inhibition of AChE and BChE, respectively. The CPF exposure had no effect on the cell viability or the expression of the differentiation markers HES5, DCX, or MAP2. However, the shRNA-knockdown of the BChE expression resulted in the decreased or delayed expression of the transcription factors HES5 and HES3. BChE may have a role in the differentiation of NSCs independent of, or in addition to, its enzymatic activity.
\end{abstract}

Keywords: neural stem cell; butyrylcholinesterase; chlorpyrifos; notch; HES5

\section{Introduction}

Chlorpyrifos (CPF) is a widely used organophosphorus class pesticide. Because of concerns relating to neurodevelopmental toxicity, the residential and public pest management use of CPF has been eliminated [1]. Epidemiological studies have suggested that CPF exposure is correlated with adverse neurodevelopmental effects involving cognition, behavior, and fetal growth [2-4]. Animal studies have evaluated the developmental neurotoxicity (DNT) of CPF using endpoints, including motor activity, cognition, emotion/anxiety, and social interaction [5-10]. However, the mechanism(s) responsible for these effects have not been determined, particularly in human neuronal precursor cells, the likely targets in the developing brain.

In animal studies, the daily administration of $5 \mathrm{mg} / \mathrm{kg}$ of CPF to pregnant mice between gestation days (GD) 7.5-11.5 resulted in morphological changes, including the thinning of the CA1 and CA3 
layers of the somatosensory cortex, the enlargement of the dentate gyrus of the hippocampus, and a decrease in the ratio of neurons and glia in the somatosensory cortex [11]. Similar morphological changes were found in juvenile rats after prenatal CPF exposure [12]. These finding were supported by recent epidemiological data, which compared high and low prenatal exposure groups and found brain changes by magnetic resonance imaging (MRI), including frontal and parietal cortical thinning [13]. Therefore, exposure to CPF during sensitive periods of development may affect the development of the nervous system.

The inhibition of acetylcholinesterase (AChE) has long been considered the primary mechanism of CPF neurotoxicity [14]. However, AChE may have a role in neurogenesis through its enzymatic activity, by interactions with other cellular factors [15-18], or through an alternate activity as an aryl acylamidase [19].

Both $\mathrm{AChE}$ and the pseudocholinesterase, butyrylcholinesterase (BChE), are expressed early in embryonic development [20] and display characteristic spatial and temporal regulation [21]. In neural crest cells, BChE is expressed during mitosis, followed by the increased expression of AChE during migration and differentiation [22]. BChE promotes proliferation prior to differentiation [23-25], while AChE may be involved in neurite outgrowth and cell adhesion [17]. Support for the role of AChE in neurite outgrowth is based on the demonstration that blockage of the peripheral site of the enzyme changes the neurite outgrowth density and may influence branching [26]. These non-classical roles for AChE and BChE have been reviewed previously $[19,26,27]$.

Neural progenitor cells (NPCs), also known as neural stem cells (NSCs), are multipotent and can differentiate into neurons, astrocytes, and oligodendrocytes [28]. The neural ectoderm, composed of NPCs, becomes two critical layers, the ventricular zone and the marginal zone, within the fluid-filled vesicle of the developing forebrain. Cell proliferation occurs through vertical cleavage, which expands the NPC population in the ventricular zone and results in the cellular migration and differentiation of one daughter cell. Therefore, in vitro differentiation of NSCs provides an opportunity to assess the potential neurotoxicity of the environmental factors, such as exposure to CPF on aspects of early neurogenesis, including proliferation and differentiation [29,30]. To model the potential effects of CPF on early neural differentiation, we chose to use human NSCs prepared from an induced pluripotent stem cell (iPSC) culture. Our goal was to characterize the NSC system, identify the increased expression of both $\mathrm{AChE}$ and $\mathrm{BChE}$, and then use mRNA markers of early commitment to neuronal differentiation to evaluate the effect of the inhibition of cholinesterases by CPF. In addition, we examined whether BChE activity or gene expression was required during early neuronal differentiation.

\section{Materials and Methods}

\section{1. iPSC and NSC Cultures}

Human foreskin fibroblasts were reprogrammed into induced pluripotent stem cells (iPSCs) by retroviral overexpression of transcription factors [31] and were grown feeder-free (i.e., without feeder cells) [32,33]. The iPSCs were characterized and grown as described previously [33].

The NSCs were prepared as described [34], except that Noggin was utilized to inhibit the BMP pathways and promote the differentiation to NSCs [35]. The iPSCS were plated on BD Matrigel ${ }^{\mathrm{TM}}$ (BD Biosciences, Billerica, MA, USA) diluted in DMEM/F12 (Gibco, ThermoFisher Scientific, Waltham, MA, USA). The cells were fed every other day with a medium consisting of 50\% MTeSR (Stem Cell Technologies, Vancouver, BC, Canada) and 50\% neural basal medium (NBM; Neurobasal ${ }^{\circledR}$ medium (Gibco), $2 \%$ B27 ${ }^{\circledR}$ supplement, 1\% insulin-transferrin-selenium (Gibco), 1\% $\mathrm{N}_{2}$ supplement (Gibco), $2 \mathrm{mM}$ L-Glutamine (Gibco), 0.5\% penicillin streptomycin (Gibco), and $500 \mathrm{ng} / \mathrm{mL}$ Noggin (Peprotech, Rocky Hill, NJ, USA). Then, 5 days after passage, the medium was changed to 100\% NBM with $500 \mathrm{ng} / \mathrm{mL}$ Noggin and fed every other day for 10 days. The cells were then passaged onto dishes coated with $20 \mu \mathrm{g} / \mathrm{mL}$ laminin (Sigma, St. Louis, MO, USA) in NBM without Noggin. At approximately $60-70 \%$ confluence, the NSCs were switched to a proliferation medium (see below) and grown until about $90 \%$ confluent. 
The NSCs were cultured in a proliferation medium containing $20 \mathrm{ng} / \mathrm{mL}$ recombinant human fibroblast growth factor-basic (FGFb; PeproTech) with 50\% DMEM/F12 with GlutaMAX (Gibco), $50 \%$ Neurobasal ${ }^{\circledR}$ medium (Gibco), and 0.5X N2 supplement (Gibco) and B27 ${ }^{\circledR}$ supplement, minus vitamin A (Gibco). The cells were plated on 1:4 Matrigel $^{\mathrm{TM}}$ diluted in DMEM/F12 and passaged with Accutase $^{\mathrm{TM}}$ (Stemcell Technologies, Inc., Vancouver, BC, Canada) at approximately $40,000 \mathrm{cells} / \mathrm{cm}^{2}$ every $3-4$ days.

\subsection{NSC Differentiation}

For the differentiation, the cells were plated in T75 flasks at 13,500 cells $/ \mathrm{cm}^{2}$ and allowed to grow to confluence. On Day 0, the cultures were switched to a differentiation medium containing $10 \mathrm{ng} / \mathrm{mL}$ brain-derived neurotrophic factor (BDNF, PeproTech, Rocky Hill, NJ, USA) in Neurobasal ${ }^{\circledR}$ plus N2 supplement. The cells were harvested using Accutase ${ }^{\mathrm{TM}}$ at Day 0 (prior to the initiation of the differentiation), Day 2, Day 4, and Day 6. The cell pellet was resuspended in phosphate buffered saline (PBS) and split 1/3 for RNA and 2/3 for the enzyme assays. The pelleted cells were rinsed well using PBS, and the residual PBS was aspirated prior to freezing at $-70^{\circ} \mathrm{C}$.

\subsection{Chlorpyrifos Exposure}

The cells were exposed to CPF (10 $\mu \mathrm{M}$; O,O-Diethyl O-3,4,6-trichloropyridnyl phosphonothioate; Chem Service Inc., West Chester, PA, USA) starting on Day 0 of the differentiation. The culture medium was changed every other day during the scheduled collection time points. The control cultures contained $1 \mu \mathrm{L} / \mathrm{mL}$ of $100 \%$ ethanol.

\subsection{Lentivirus Production and shRNA Knockdown}

For the BChE knockdown, the Mission ${ }^{\circledR}$ shRNA TRC2 lentiviral vector plasmid was purchased from Sigma (TRC number TRCN0000427955, Clone ID NM_000055.2-439s21c1) along with the non-target shRNA control plasmid SHC216. Addgene (Cambridge, MA, USA) third-generation packaging plasmids were transfected at a ratio of 4:2:1:1 of the target vector, MDLg/RRE, VSVg-MD2g, and RSV-REV, respectively, into HEK293T cells. The culture medium was changed daily, harvested for the virus on Day 2 and 3 (at approximately 48 and $72 \mathrm{~h}$ post-transfection), and stored at $4{ }^{\circ} \mathrm{C}$. The medium was then centrifuged at $200 \times g$ to remove cellular debris and virus concentrated by centrifuging at 25,000 rpm for $2 \mathrm{~h}$. The supernatant was removed, and the virus was resuspended in $180 \mu \mathrm{L}$ DMEM/F12 overnight and stored at $-70{ }^{\circ} \mathrm{C}$ prior to use.

To quantify the virus, the Sigma-Aldrich Lentiviral Titer p24 ELISA protocol was used, and the viral supernatants were assayed using the Retrotek HIV-1 p24 Antigen ELISA (0801111, Zeptometrix Corp., Buffalo, NY, USA).

For the knockdown experiments, the cultures were seeded at a density of approximately 13,500 cells $/ \mathrm{cm}^{2}$ in 6-well plate culture dishes and then infected the next day with 6 titer units (TU) per cell in a medium containing $8 \mu \mathrm{g} / \mathrm{mL}$ protamine sulfate (Sigma Aldrich, Saint Louis, MO, USA). The medium was changed the next day to remove the virus and protamine sulfate, and the lysates for RNA were collected on Day 0 and Day 6 of the differentiation.

\subsection{Quantitative Real-Time Polymerase Chain Reaction}

RNA was isolated using the RNeasy ${ }^{\circledR}$ Mini Kit (Qiagen, Hilden, Germany) using on-column DNase treatment. $0.8 \mu \mathrm{g}$ RNA was reverse transcribed using SuperScript ${ }^{\mathrm{TM}}$ (Invitrogen, Carlsbad, CA, USA), using random primers. Quantitative-PCR (qPCR) was performed using Power SYBR ${ }^{\circledR}$ Green PCR Master Mix (Applied Biosystems, Foster City, CA, USA). The relative mRNA expression was calculated using the $2^{-\Delta \Delta C t}$ method [36], using TBP (TATA binding protein; which had the least variance among all the tested endogenous control targets) as a normalizing gene. The primer sequences are listed in Table 1. 
Table 1. List of primers for qPCR. All sequences are from $5^{\prime}$ to $3^{\prime}$.

\begin{tabular}{ccc}
\hline Gene & Forward Primer & Reverse Primer \\
\hline ACHE & GGGGCTCAGCAGTACGTTAG & CGGTGGCGCTGAGCAATTT \\
BCHE & CTTTGTTGCAGAGAATCGGAAATC & CGGTGGCGCTGAGCAATTT \\
DCX & GACTCAGCAAACGGAACCTCC & GAATCACCAAGCGAGTCCGA \\
MAP2 & TGCGCTGATTCTTCAGCTTG & TGTGTCGTGTTCTCAAAGGGT \\
HES5 & CGGCACCAGCCCAACTCCAA & GCGACGAAGGCTTTGCTGTGC \\
HES1 & GAAAGATAGCTCGCGGCATT & TACTTCCCCAGCACACTTGG \\
HES3 & CTGATGGAGAAAAAGCGCCG & TTCCGGATCTGGTGCGAGTA \\
DELTA4 & TGTGCAAGAAGCGCAATGAC & AAGACAGATAGGCTGTTGGCA \\
JAG1 & GTCTCAACGGGGGAACTTGT & GCGTGCTCAGCAATTTCACA \\
TBP & AAGACCATTGCACTTCGTGCCC & TGGACTGTTCTTCACTCTTGGCTCC \\
CYP3A7 & TTGAAACACGTCTTTGGGGC & TGAGAGAACGAATGGATCTAATGGA \\
POR & TGCCAGCGTTTCATGATCAAC & GAGACCCACGATGAGCGAAA \\
\hline & &
\end{tabular}

\subsection{Butyrylcholinesterase and Acetylcholinesterase Enzyme Assays}

A 96-well microplate assay was developed from the modification of the methods described previously [5]. The frozen cell pellets were re-suspended in 200-300 $\mu \mathrm{L}$ of $50 \mathrm{mM}$ Tris buffer $(\mathrm{pH} 7.4$ at $37^{\circ} \mathrm{C}$ ). The cell pellets were sonicated using a Labsonic ${ }^{\circledR} \mathrm{M}$ (Sartorius Stedim Biotech, Göttingen, Germany). Between 15-30 $\mu \mathrm{g}$ of protein was assayed in duplicate spectrophotometrically, using $1 \mathrm{mM}$ acetylthiocholine iodide (Sigma-Aldrich, St. Louis, MO, USA) as the substrate for AChE activity and 2 mM S-Butyrylthiocholine iodide (Sigma-Aldrich, St. Louis, MO, USA) as the substrate for BChE activity. The chromagen 5,5'-dithio-bis(nitrobenzoic acid) (DTNB, Sigma-Aldrich, St. Louis, MO, USA) was used at a final assay concentration of $0.3 \mathrm{mM}$, and $10 \mu \mathrm{M}$ of eserine sulfate (Sigma-Aldrich, St. Louis, MO, USA) was used in duplicate parallel samples to correct for non-enzymatic substrate hydrolysis. The microplate containing the sample, chromagen, and an inhibitor (if required) was pre-incubated for $10 \mathrm{~min}$ at $37^{\circ} \mathrm{C}$ with shaking. The substrate was added, and the microplate was read at $412 \mathrm{~nm}$ for $20 \mathrm{~min}$ at $41-\mathrm{sec}$ intervals with mixing. The specific activity was calculated as nmoles product formed per minute per mg protein using the extinction coefficient $14,150 \mathrm{M}^{-1} \mathrm{~cm}^{-1}$.

\subsection{Immunocytochemistry and Microscopy}

The NSCs were plated on poly-D-lysine (PDL, Sigma)/laminin (Sigma)-coated $12 \mathrm{~mm}$ glass coverslips at 400,000 cells/well on Day 2 of the differentiation and allowed to differentiate for 90 days. The cultures were fed with the differentiation media containing $1 \mu \mathrm{g} / \mathrm{mL}$ laminin. On Day 90, the cultures were then fixed for $30 \mathrm{~min}$ at room temperature in $4 \%$ paraformaldehyde, followed by an incubation for $1 \mathrm{~h}$ with $4 \%$ normal goat serum and $0.01 \%$ triton $\mathrm{x}-100$ in PBS to permeabilize and block. The cells were then incubated at $4{ }^{\circ} \mathrm{C}$ overnight with the following antibodies: MAP2 (microtubule-associated protein 2, Millipore, 1:1000), neuronal Class III $\beta$-tubulin (TUJ1, Covance, Princeton, NJ, USA, 1:2000), synaptophysin (Millipore, Burlington, MA, USA, 1:500), vesicular glutamate transporter 1 (Vglut, Synaptic Systems, Goettingen, Germany, 1:500), and glial fibrillary acidic protein (GFAP, Dako/Agilent, Santa Clara, CA, USA, 1:1000). Then, the removal of the primary antibody and triplicate PBS washes were performed. The next day, the cultures were incubated for $1 \mathrm{~h}$ at room temperature with the following secondary antibodies: Alexa Fluor ${ }^{\circledR} 488$ conjugate (Goat anti-Rabbit IgG; Goat anti-Mouse IgG2A) and Alexa Fluor ${ }^{\circledR} 594$ conjugate (Goat anti-Mouse IgG1) at a 1:500 concentration. The nuclei were counterstained with DAPI $(0.3 \mu \mathrm{g} / \mathrm{mL}$, Roche Diagnostics, Indianapolis, IN, USA) and rinsed well with PBS and then distilled water prior to mounting.

\subsection{Statistical Analysis}

The experiments were performed at independent times and cell passages, and each independent differentiation was considered to be a biological replicate. The data were analyzed using a one-way ANOVA model to account for batch variation followed by Tukey multiple comparisons of means to assess changes in mRNA expression and enzyme activity. For CPF- and lentivirus-treated samples, 
paired $t$-tests were used for each time point to analyze the expression differences between the treatment and control. The data are presented as bar graphs with error bars representing the mean \pm standard error of the mean (SEM).

\section{Results}

\subsection{NSC Model of Early Neuronal Differentiation}

The NSCs were prepared from human iPSCs by switching from a proliferative medium containing FGFb to a medium containing BDNF that favors differentiation (Figure 1A). During the initial six days of the differentiation, the cells transformed from a homogenous appearance to one of clustered cell bodies, with the outgrowth of the processes visible between the clusters (Figure 1B). To assess the NSC differentiation during this initial phase, three mRNAs were chosen as markers (Figure 1C). HES5 was identified from an RNAseq analysis of similarly differentiating human embryonic stem cell (ESC)-derived NSCs [37]. HES5 is a repressive transcription factor, which regulates neuronal differentiation and, along with HES1, is an effector of the Notch pathway [38]. MAP2 is a cytoskeletal protein that is associated with microtubules in neurons [39]. Doublecortin (DCX) is a microtubule-associated protein, which is expressed by migrating neuroblasts during differentiation [40]. All the mRNAs exhibited significant upregulation on Day 4 and Day 6, consistent with neuronal differentiation. The results indicate that the NSC began the process of differentiating into neurons within 2-6 days after the BDNF addition and FGFb withdrawal, and this provides a model for studying key mechanisms during the initial commitment to neurons.

A

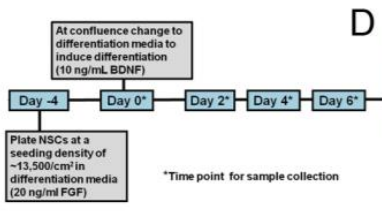

B
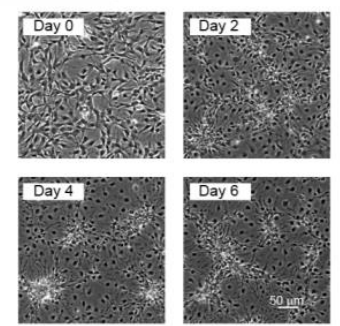

C

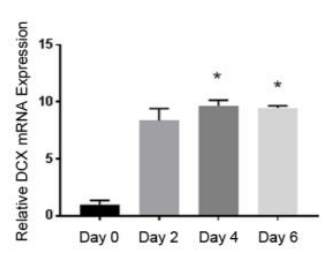

D
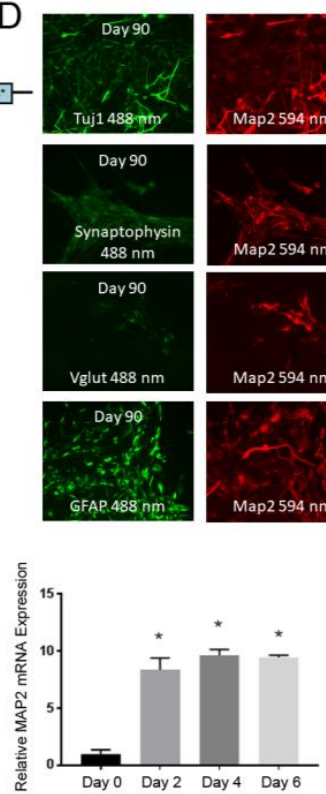
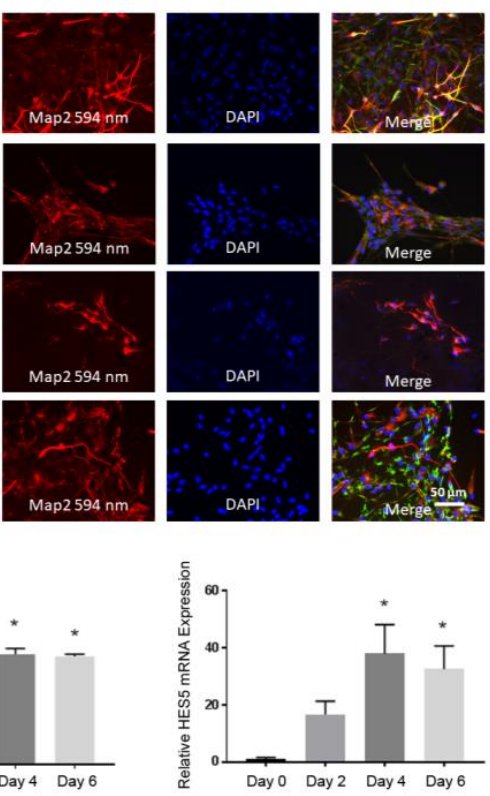

Figure 1. Characterization of the neural stem cell (NSC) model of differentiation. (A) The overview of the experimental timeline of the early differentiation. (B) Phase-contrast microscopy showing the morphological changes of NSC in the first few days after the induction of the differentiation. (C) To assess the early differentiation, the relative mRNA expression of the differentiation markers DCX, MAP2, and HES5 were determined by qPCR. All three markers increased significantly relative to Day 0 . The results depict the mean $\pm \operatorname{SEM}(n=3-5)$ analyzed using a one-way ANOVA model to account for batch variation followed by Tukey multiple comparisons of means $\left({ }^{*} p<0.05\right)$. (D) To confirm the multipotency of NSC and that differentiation produces mature neurons and glia, the cultures were fixed and stained immunocytochemically after 90 days of differentiation. All the cultures consisted of cells positive for Tuj1, synaptophysin, and Vglut (punctate staining, counterstained for MAP2) or GFAP (indicative of astrocytes, non-overlapping with MAP2). BDNP: brain-derived neurotrophic factor. 
To confirm the appropriate cellular identity of multipotent NSCs, that they produce neurons and glia, we examined the cultures differentiated for much longer periods of time for the production of mature neuronal morphologies and markers. In our previous experience with stem cell-derived NSCs [37], we learned that $\sim 90$ days normally produces the robust expression of markers to evaluate the neurons and astrocytes. Oligodendrocyte markers, such as MBP, were not evaluated. Cultures immunocytochemically stained after 90 days of differentiation indicated cells expressing the neuronal markers $\beta$ III-tubulin (TuJ1), synaptophysin, and vesicular glutamate transporter (Vglut), each overlapping microtubule-associated protein 2 (MAP2), and the astrocytic marker GFAP, which did not overlap MAP2 (Figure 1D). The detection of diffuse synaptophysin immunoreactivity in the cytoplasm was consistent with neuronal expression prior to synaptogenesis, which would produce a more punctate staining. The large number of Vglut/MAP2 double-positive cells was consistent with the presence of glutamatergic neurons in these cultures. Some cells also stained positive for GFAP, which did not co-localize with MAP2, indicating astrocytes. GFAP- and MAP2-stained cells occurred in similar proportions, indicating a mixture of astrocytes and excitatory neuronal lineages. The expression of neuron and astrocyte markers at later time points indicated that the NSCs were multipotent and that the differentiation protocol was effective.

\subsection{Butyrylcholinesterase mRNA Expression and Activity Progressively Increases During Differentiation}

To determine whether $\mathrm{AChE}$ and $\mathrm{BChE}$ are regulated during early NSC differentiation, mRNA expression and enzyme activities were detected using qPCR and spectrophotometric assays, respectively (Figure 2). During NSC differentiation, the BChE mRNA expression and activity significantly increased during the initial six days. The AChE mRNA expression and activity were unchanged relative to Day 0. This indicated that the BChE mRNA expression and activity were upregulated along with other differentiation markers (HES5, DCX, and MAP2), suggesting that BChE may play a role in the early differentiation of NSCs.
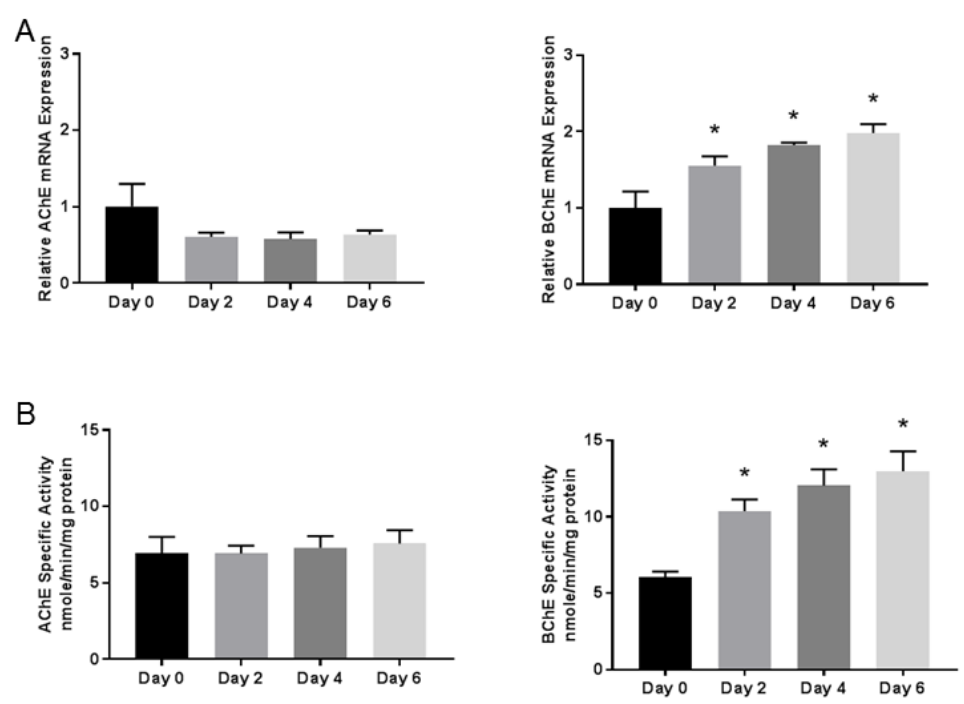

Figure 2. Acetylcholinesterase (AChE) and butyrylcholinesterase (BChE) activity and expression during early NSC differentiation. (A) The relative mRNA expression of the enzymes AChE and BChE were determined by quantitative real-time PCR. The BChE mRNA expression increased significantly relative to Day 0 on all subsequent time points shown, while AChE was detected but unchanged over time. (B) The AChE and BChE specific activity was assayed using a kinetic spectrophotometric assay. The BChE specific activity increased significantly on all subsequent time points relative to Day 0 , mirroring the mRNA expression. The data represent the mean $\pm \operatorname{SEM}(n=5-6)$. The data were analyzed using a one-way ANOVA model to account for batch variation, followed by Tukey multiple comparisons of means $\left({ }^{*} p<0.05\right)$. 


\subsection{Cholinesterase Inhibition by Chlorpyrifos Does Not Affect Neuronal Marker Expression}

To test the hypothesis that the CPF inhibition of cholinesterase affects early neurogenesis, the NSC cultures were treated with $10 \mu \mathrm{M} \mathrm{CPF}$. There was no effect on cell viability (as assayed with Alamar Blue $^{\circledR}$, not shown). The CPF inhibited the AChE and BChE activity by $82 \%$ and $92 \%$, respectively (Figure 3A). This inhibition of activity did not change the expression of AChE or BChE mRNAs relative to the control group (Figure 3B). However, mRNA markers of neuronal differentiation (HES5, MAP2, and DCX) were not altered by the CPF treatment (Figure 3C).

A

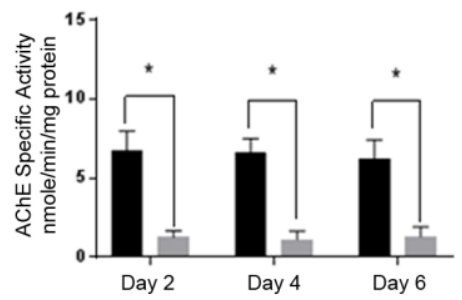

B

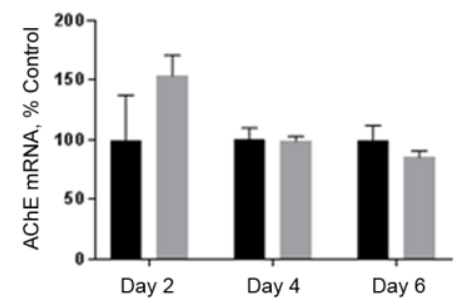

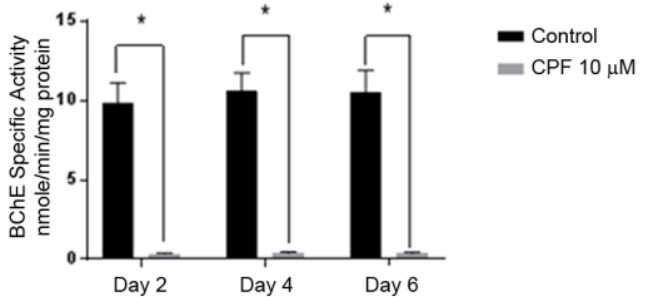

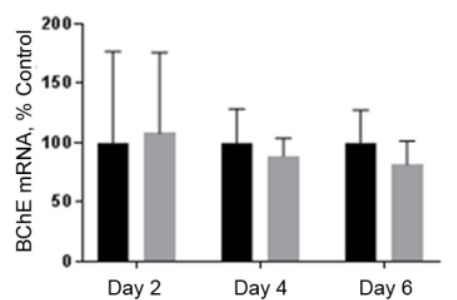

C
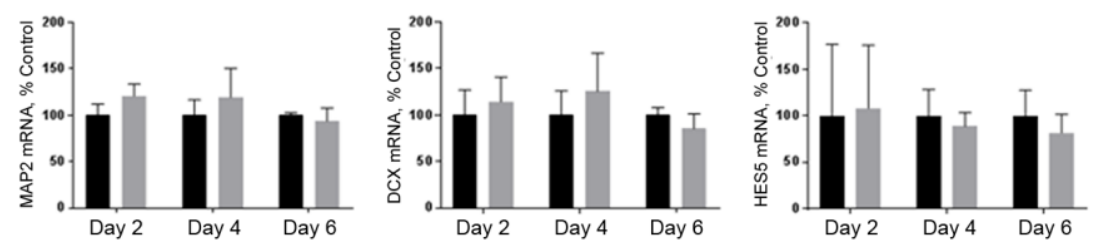

Figure 3. Inhibition of $\mathrm{AChE}$ and $\mathrm{BChE}$ by chlorpyrifos (CPF). The cell cultures were exposed continuously to $10 \mu \mathrm{M}$ CPF starting on Day 0 (see Figure 1A Top right). (A) The AChE and BChE specific activity was assayed using a kinetic spectrophotometric assay. Both $\mathrm{AChE}$ and $\mathrm{BChE}$ were inhibited by $82 \%$ and $92 \%$, respectively. (B) The relative mRNA expression levels of the enzymes AChE and BChE and (C) the differentiation markers MAP2, DCX, and HES5 were determined by quantitative real-time PCR. There were no significant differences between the control and $10 \mu \mathrm{M}$ CPF exposure groups. The data represent the mean $\pm \operatorname{SEM}(n=3)$. The data were analyzed using paired $t$-tests for each time point to account for batch variation. $\left({ }^{*} p<0.05\right)$.

To assess the potential for the metabolic activation of CPF in NSCs, CYP450 and CP450 reductase (POR) mRNAs were measured by qPCR. Both CYP3A7 and POR mRNAs were detected at all time points, with cycle threshold $(\mathrm{Ct})$ values of approximately 31.5 and 24.5, respectively, indicating a robust signal (results not shown). The likely presence of the metabolizing enzymes and the observed cholinesterase activity inhibition indicates that this model of NSC differentiation is likely to be capable of bioactivating CPF.

\subsection{Knockdown of BChE mRNA Alters HES5 mRNA Expression}

Because the $\mathrm{CPF}$ inhibition of the $\mathrm{BChE}$ activity did not affect the markers of early differentiation, we considered whether the $\mathrm{BChE}$ expression was required for normal differentiation. To test this alternative hypothesis that the non-enzymatic functions of $\mathrm{BChE}$ regulate neurogenesis, the NSCs were infected with lentivirus expressing $\mathrm{BChE}$ or the negative control shRNA $72 \mathrm{~h}$ prior to the induction 
of the differentiation on Day 0 (Figure $4 \mathrm{~A}$ ). The knockdown of the mRNA was calculated to be $72 \%$ (Figure 4B). The BChE knockdown resulted in a significant upregulation of the AChE mRNA relative to the control on Day 6 (Figure 4C), with no change in MAP2 (Figure 4D) or DCX (Figure 4E) mRNAs but with a downregulation of HES5 on Day 0 (Figure 4F). We conclude that the BChE mRNA knockdown resulted in the perturbed or delayed expression of the differentiation marker HES5.
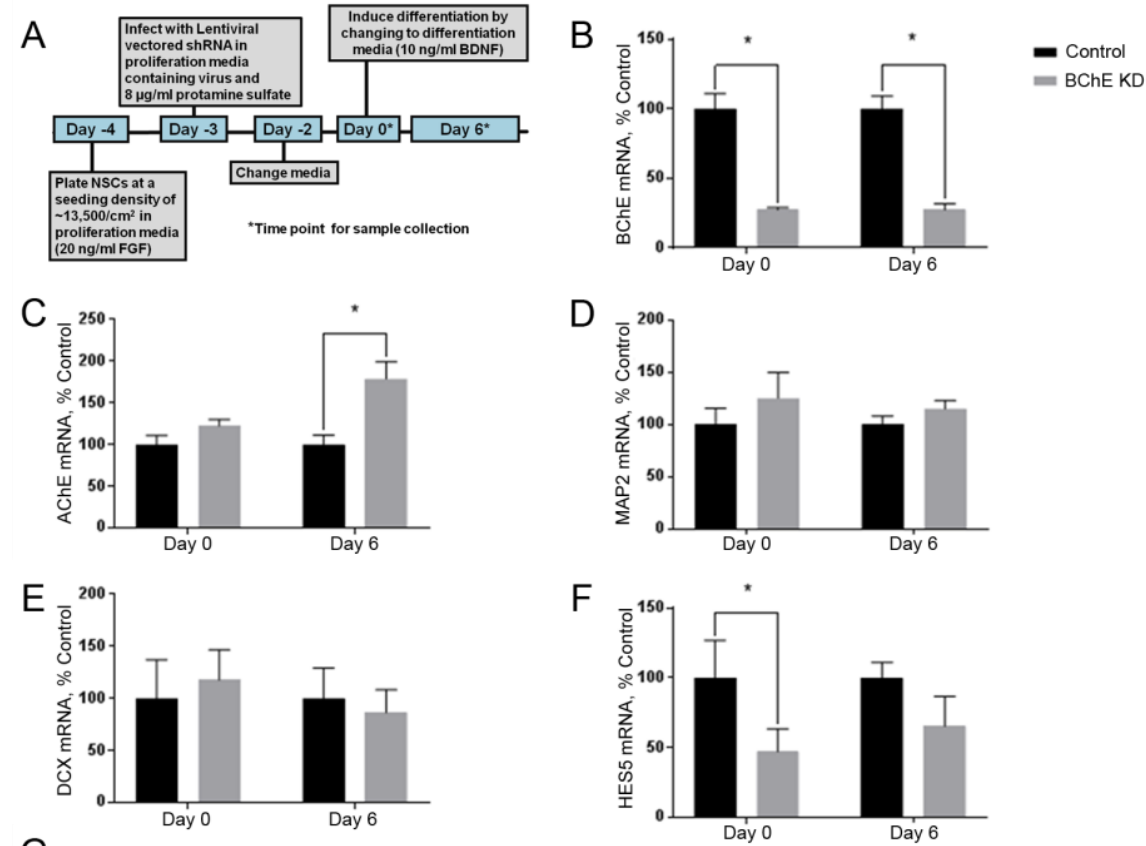

G
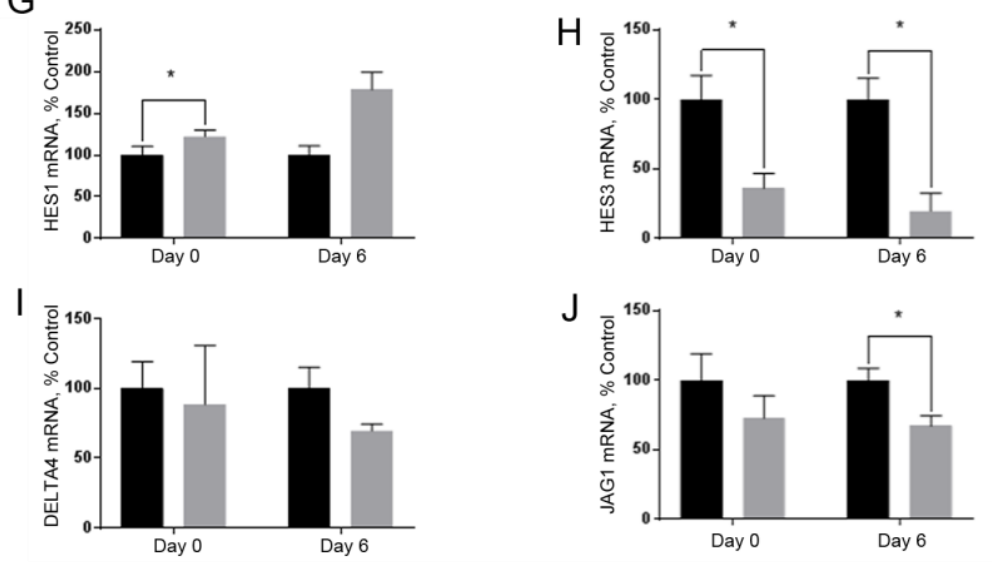

Figure 4. BChE shRNA knockdown. (A) An overview of the experimental timeline of the differentiation. The relative mRNA expression levels of the enzymes (B) BChE and (C) AChE and the differentiation markers (D) MAP2, (E) DCX, (F) HES5, (G) HES1, (H) HES3, the Notch ligands (I) DELTA4, and (J) JAG1 were determined by qPCR. The BChE knockdown was calculated to be $72 \%$. The AChE expression was significantly increased on Day 6 relative to the control. Of the early differentiation markers, only HES5 was significantly decreased on Day 0 of the differentiation, but the components of the Notch signaling pathway (HES1, HES3, and JAG1) were affected by the BChE knockdown. The data represent the mean $\pm \operatorname{SEM}(n=4)$. The data were analyzed using paired $t$-tests for each time point to account for batch variation. $\left({ }^{*} p<0.05\right)$.

Because HES5 is regulated by the Notch pathway, we assayed the mRNA expression of the additional Notch pathway genes HES1, HES3, and the Notch ligands JAG1 and DELTA4 following the BChE knockdown (Figure 4G-J). HES1 was upregulated on Day 0 relative to the control (Figure 4G). The Day 0 sample was taken prior to the BDNF addition and FGFb withdrawal. HES3 was 
downregulated both on Day 0 and Day 6 (Figure $4 \mathrm{H}$ ), and the Notch ligand DELTA4 was unaffected (Figure 4I), but JAG1 was down regulated on Day 6 (Figure 4J). The results indicate that the BChE mRNA knockdown, but not the inhibition by CPF, produced changes in the mRNA expression of several developmental and Notch pathway genes, suggesting that BChE likely has a non-enzymatic role in NSC differentiation.

\section{Discussion}

We established an iPSC-derived NSC human cell culture model of early neuronal differentiation as a model for testing neurotoxicity in a human neural progenitor. This system was used to probe the DNT of CPF and to assess the function of BChE early in neurogenesis. The NSC model consists of both a proliferative phase and a differentiation phase, with differentiation characterized by morphological changes and increased expression of the neuronal structural markers MAP2, DCX, and the transcription factor HES5. These three markers were chosen from a comprehensive RNAseq analysis of NSC differentiation in an earlier study [37] as preliminary indicators for the changes occurring during the initial phase of neurogenesis. The differentiation was induced by the withdrawal of pro-mitotic FGFb and the addition of differentiation-promoting BDNF. Much later in the process, after 90 days, the cells stained positive for both neuronal markers, including TuJ1, synaptophysin, Vglut, and MAP2, as well as the non-overlapping astrocytic marker GFAP (Figure 1C), as direct proof that the NSC cultures were multipotent. This model also displayed the expression of both CPF targets BChE and AChE, although only the BChE mRNA expression and activity was increased during the six days of differentiation. Of course, the cholinesterase activity in these isolated cells may not represent the levels seen during intact brain development, but the increase in BChE likely reflects a component or at least an indicator of a developmental mechanism. BChE is known to be expressed at higher levels than AChE in early embryonic development, and, in neural crest cells, BChE is expressed during mitosis and AChE is expressed during migration and through differentiation [21]. This characteristic early expression of $\mathrm{BChE}$ during early differentiation is consistent with the hypothesis that BChE may have a role in early NSC differentiation.

To determine whether the catalytic activity of AChE and BChE is essential for early NSC differentiation, the cells were treated continuously with a concentration of CPF sufficient to inhibit the $\mathrm{AChE}$ and BChE activities but not enough to cause overt cytotoxicity. Interestingly, we were able to detect the expression of both the CYP3A7 and CYP450 reductase (POR) mRNAs in the NSC model, likely indicating the capacity to convert CPF to its more toxic oxon. In preliminary studies, we had tested the oxon form of CPF and saw no effect, likely due to interactions of the oxon with the Matrigel layer supporting the NSC cultures. In any case, CPF appropriately inhibited the cholinesterase enzyme activities (Figure 3). No activities other than cholinesterase were investigated, so there remains the possibility that CPF or its oxon may affect another pathway, although no effects on the endpoints chosen for study related to neurogenesis were observed.

Others have devised strategies to test neurotoxicity in cellular models of neural progenitors or neurons. In a study using NSCs derived from human umbilical cord blood to model DNT, minimal toxicity was observed at $10 \mu \mathrm{M} \mathrm{CPF}$, although the cells differentiated more towards an astrocytic phenotype and showed a partial decrease in viability [41]. Another recent study used a commercial, immortalized human cell line to test the epigenetic effects of CPF in both proliferating and differentiating NSCs, and the toxic effects were not detected at concentrations below $57 \mu \mathrm{M}$ [42]. Neither study quantified the cholinesterase activity. Another study used adipose-derived stem cells to model CPF toxicity [43] but used a much higher dose of CPF (500 $\mu \mathrm{M})$, finding decreased viability in differentiating cells. One study examined differentiation outcomes in embryonic stem cell-derived NPCs, finding reduced proportions of glial cells upon exposure to 10-30 $\mu \mathrm{M} \mathrm{CPF} \mathrm{[44].} \mathrm{Others}$ used neuron-like cell lines, including N2a and PC12 cells, identifying the cellular effects, such as neurite retraction $[45,46]$, which would reflect events much later than the initial NSC differentiation modeled here. Our goal was to identify the specific mechanisms affected early in NSC differentiation, 
because these events are likely to cause changes in the differentiation choice, such as the reduced glial differentiation [43] or changes in the neuronal circuitry due to shifted differentiation patterns.

The CPF inhibition of both $\mathrm{AChE}$ and $\mathrm{BChE}$ activities, however, did not alter the expression of the early differentiation markers MAP2, DCX, or HES5 (Figure 3C). The dose of $10 \mu \mathrm{M} \mathrm{CPF}$ was chosen due to the lack of observed cytotoxicity and to result in greater than $80 \%$ inhibition of ChEs. However, it is within the range of doses found to alter the eventual balance of mature cell types produced later in development [44]. Our data clearly demonstrate that CPF did not affect the initial molecular mechanisms during early neurogenesis from progenitor cells, even with greater than $80 \%$ ChE inhibition observed.

One possibility was that neither AChE nor BChE are required for early neurogenesis. Because we observed an increase in mRNA and activity for $\mathrm{BChE}$ during this phase (Figure 2), we considered that the BChE protein may be required for the differentiation of NSCs. To test this, we used lentiviral-encoded shRNA to knockdown BChE. The BChE knockdown reduced the expression of HES5 mRNA by over $50 \%$ but did not affect MAP2 or DCX mRNAs, suggesting a selective effect. Because HES5 is known to be regulated by the Notch signaling pathway, we also determined that HES1 and JAG1 were altered (Figure 4G,J). Interestingly, prior to the initiation of the differentiation, the BChE knockdown reduced HES3 (Figure 4H) and HES5 (Figure 4F) mRNA levels and increased HES1 (Figure 4G) mRNA expression, suggesting that endogenous BChE expression affects HES signaling in NSCs. The repressor-type basic helix-loop-helix (bHLH) genes HES1, HES3, and HES5 played a critical role in NSC differentiation and maintenance [47]. Activating the bHLH target genes, including Mash1, Math and Neurogenin, promoted neurogenesis, whereas the repressor bHLH genes promoted gliogenesis, which were formed later in neural stem cell differentiation.

HES1 and HES5 are regulated by the Notch pathway [48], but HES3 is not [49]. HES1 and HES5 can compensate for each other, although HES1/HES5 double knockout mice have shown decreased maintenance of glial cells and increased early neurogenesis [47]. Triple knockout HES1/HES3/HES5 mice have a more severe phenotype, which results in the premature differentiation of stem cells in neurons and a loss of other cell types, including astrocytes and oligodendrocytes [50]. Because HES5 expression was decreased with the BChE knockdown, mediation by Notch pathway proteins was likely. The notch ligand JAG1 was decreased on Day 6 of the differentiation. JAG1 is involved postnatal and adult neurogenesis in the dentate gyrus [51], and astrocytes have been shown to decrease neurogenesis though Notch/JAG1 signaling [52].

Based on these results, we propose that BChE may interact with other proteins in NSCs and early during the initial NSC differentiation through a non-enzymatic mechanism. It has been suggested that ChE may act as cell adhesion molecules (CAMs). CAMs that function in nervous system development have an extracellular domain, which displays sequence homology to ChEs [53], and the X-ray crystallography structure of human BChE had a structural homology with neuroligins [54]. The knockdowns indicated that the $\mathrm{BChE}$ antisense treatment reduced proliferation and increased differentiation and apoptosis in chick retinae [23,25] and in a rat oligodendroglia cell line [24]. BChE antisense transfection reduced proliferation, increased protein kinase C (PKC), and pushed the cells towards an astrocytic phenotype. Finally, the knockdown of BChE in R28 cells, a retinal rat cell line with pluripotent characteristics, increased the AChE expression, and this "counter-regulation" was tightly controlled through transcription factors c-fos and P90RSK1 [55]. The BChE knockdown perturbed PKC and ERK signaling, suggesting that coordinated ChE expression is involved in cell fate determination. Further research is required to fully elucidate the relative roles of $\mathrm{AChE}$ and $\mathrm{BChE}$ protein in NSC differentiation and whether this process may be targeted by environmental toxicants to disrupt NSC differentiation.

In conclusion, we established a human iPSC-derived NSC model of early differentiation to probe the DNT of CPF. Although CPF inhibited the enzymatic activity of both AChE and BChE, no effects on NSC toxicity or on the mRNA expression of early differentiation markers HSE5, MAP2, and DCX were found. On the other hand, the shRNA knockdown of BChE resulted in the decreased mRNA expression 
of HES5 and changes in the expression of the related genes HES3, HES1, and JAG1. These results suggest a novel and potentially non-enzymatic role of BChE in NSC differentiation mechanisms through the regulation of HES genes, possibly through the Notch pathway.

Author Contributions: J.R.R. and R.P.H conceived the study; A.T.K. performed experiments. All authors prepared the manuscript.

Funding: This research received no external funding.

Acknowledgments: This work was supported by a pilot award from P30 ES005022 and by R01 ES026057 (J.R.R. and R.P.H).

Conflicts of Interest: The authors disclose no conflicts of interest.

\section{References}

1. Eaton, D.L.; Daroff, R.B.; Autrup, H.; Bridges, J.; Buffler, P.; Costa, L.G.; Coyle, J.; McKhann, G.; Mobley, W.C.; Nadel, L.; et al. Review of the toxicology of chlorpyrifos with an emphasis on human exposure and neurodevelopment. Crit. Rev. Toxicol. 2008, 38 (Suppl. S2), 1-125. [CrossRef] [PubMed]

2. Rauh, V.; Arunajadai, S.; Horton, M.; Perera, F.; Hoepner, L.; Barr, D.B.; Whyatt, R. Seven-year neurodevelopmental scores and prenatal exposure to chlorpyrifos, a common agricultural pesticide. Environ. Health Perspect. 2011, 119, 1196-1201. [CrossRef] [PubMed]

3. Berkowitz, G.S.; Wetmur, J.G.; Birman-Deych, E.; Obel, J.; Lapinski, R.H.; Godbold, J.H.; Holzman, I.R.; Wolff, M.S. In utero pesticide exposure, maternal paraoxonase activity, and head circumference. Environ. Health Perspect. 2004, 112, 388-391. [CrossRef] [PubMed]

4. Gunier, R.B.; Bradman, A.; Harley, K.G.; Kogut, K.; Eskenazi, B. Prenatal residential proximity to agricultural pesticide use and IQ in 7-year-old children. Environ. Health Perspect. 2017, 125. [CrossRef] [PubMed]

5. Richardson, J.; Chambers, J. Effects of gestational exposure to chlorpyrifos on postnatal central and peripheral cholinergic neurochemistry. J. Toxicol. Environ. Health A 2003, 66, 275-289. [CrossRef] [PubMed]

6. Richardson, J.R.; Chambers, J.E. Effects of repeated oral postnatal exposure to chlorpyrifos on cholinergic neurochemistry in developing rats. Toxicol. Sci. 2005, 84, 352-359. [CrossRef] [PubMed]

7. Venerosi, A.; Calamandrei, G.; Ricceri, L. A social recognition test for female mice reveals behavioral effects of developmental chlorpyrifos exposure. Neurotoxicol. Teratol. 2006, 28, 466-471. [CrossRef] [PubMed]

8. Venerosi, A.; Ricceri, L.; Tait, S.; Calamandrei, G. Sex dimorphic behaviors as markers of neuroendocrine disruption by environmental chemicals: The case of chlorpyrifos. Neurotoxicology 2012, 33, 1420-1426. [CrossRef] [PubMed]

9. De Felice, A.; Venerosi, A.; Ricceri, L.; Sabbioni, M.; Scattoni, M.L.; Chiarotti, F.; Calamandrei, G. Sex-dimorphic effects of gestational exposure to the organophosphate insecticide chlorpyrifos on social investigation in mice. Neurotoxicol. Teratol. 2014, 46, 32-39. [CrossRef] [PubMed]

10. Venerosi, A.; Tait, S.; Stecca, L.; Chiarotti, F.; De Felice, A.; Cometa, M.F.; Volpe, M.T.; Calamandrei, G.; Ricceri, L. Effects of maternal chlorpyrifos diet on social investigation and brain neuroendocrine markers in the offspring-A mouse study. Environ. Health 2015, 14, 32. [CrossRef] [PubMed]

11. Chen, X.P.; Jin, J.L.; Li, C.W.; Wang, F.S. Effects of low concentration of chlorpyrifos prenatal exposure on generation mouse brain hippocampus and somatosensory cortex. Chin. J. Ind. Hyg. Occup. Dis. 2009, 27, $557-559$.

12. Roy, T.S.; Sharma, V.; Seidler, F.J.; Slotkin, T.A. Quantitative morphological assessment reveals neuronal and glial deficits in hippocampus after a brief subtoxic exposure to chlorpyrifos in neonatal rats. Dev. Brain Res. 2005, 155, 71-80. [CrossRef] [PubMed]

13. Rauh, V.A.; Perera, F.P.; Horton, M.K.; Whyatt, R.M.; Bansal, R.; Hao, X.; Liu, J.; Barr, D.B.; Slotkin, T.A.; Peterson, B.S. Brain anomalies in children exposed prenatally to a common organophosphate pesticide. Proc. Natl. Acad. Sci. USA 2012, 109, 7871-7876. [CrossRef] [PubMed]

14. Costa, L.G.; Giordano, G.; Guizzetti, M.; Vitalone, A. Neurotoxicity of pesticides: A brief review. Front. Biosci. 2008, 13, 1240-1249. [CrossRef] [PubMed]

15. Yang, D.; Howard, A.; Bruun, D.; Ajua-Alemanj, M.; Pickart, C.; Lein, P.J. Chlorpyrifos and chlorpyrifos-oxon inhibit axonal growth by interfering with the morphogenic activity of acetylcholinesterase. Toxicol. Appl. Pharmacol. 2008, 228, 32-41. [CrossRef] [PubMed] 
16. Slotkin, T.A.; Seidler, F.J.; Fumagalli, F. Targeting of neurotrophic factors, their receptors, and signaling pathways in the developmental neurotoxicity of organophosphates in vivo and in vitro. Brain Res. Bull. 2008, 76, 424-438. [CrossRef] [PubMed]

17. Paraoanu, L.E.; Layer, P.G. Acetylcholinesterase in cell adhesion, neurite growth and network formation. FEBS J. 2008, 275, 618-624. [CrossRef] [PubMed]

18. Johnson, G.; Moore, S.W. Human acetylcholinesterase binds to mouse laminin-1 and human collagen IV by an electrostatic mechanism at the peripheral anionic site. Neurosci. Lett. 2003, 337, 37-40. [CrossRef]

19. Vogel-Hopker, A.; Sperling, L.E.; Layer, P.G. Co-opting functions of cholinesterases in neural, limb and stem cell development. Protein Pept. Lett. 2012, 19, 155-164. [PubMed]

20. Drews, U. Cholinesterase in embryonic development. Prog. Histochem. Cytochem. 1975, 7, 1-52. [CrossRef]

21. Layer, P.G.; Sporns, O. Spatiotemporal relationship of embryonic cholinesterases with cell proliferation in chicken brain and eye. Proc. Natl. Acad. Sci. USA 1987, 84, 284-288. [CrossRef] [PubMed]

22. Layer, P.G.; Willbold, E. Novel functions of cholinesterases in development, physiology and disease. Prog. Histochem. Cytochem. 1995, 29, 1-94. [CrossRef]

23. Robitzki, A.; Mack, A.; Chatonnet, A.; Layer, P.G. Transfection of reaggregating embryonic chicken retinal cells with an antisense $5^{\prime}$-DNA butyrylcholinesterase expression vector inhibits proliferation and alters morphogenesis. J. Neurochem. 1997, 69, 823-833. [CrossRef] [PubMed]

24. Robitzki, A.; Doll, F.; Richter-Landsberg, C.; Layer, P.G. Regulation of the rat oligodendroglia cell line OLN-93 by antisense transfection of butyrylcholinesterase. Glia 2000, 31, 195-205. [CrossRef]

25. Mack, A.; Robitzki, A. The key role of butyrylcholinesterase during neurogenesis and neural disorders: An antisense-5'butyrylcholinesterase-DNA study. Prog. Neurobiol. 2000, 60, 607-628. [CrossRef]

26. Zimmerman, G.; Soreq, H. Termination and beyond: Acetylcholinesterase as a modulator of synaptic transmission. Cell Tissue Res. 2006, 326, 655-669. [CrossRef] [PubMed]

27. Layer, P.G.; Klaczinski, J.; Salfelder, A.; Sperling, L.E.; Thangaraj, G.; Tuschl, C.; Vogel-Hopker, A. Cholinesterases in development: Ache as a firewall to inhibit cell proliferation and support differentiation. Chem. Biol. Interact. 2013, 203, 269-276. [CrossRef] [PubMed]

28. Gage, F.H.; Temple, S. Neural stem cells: Generating and regenerating the brain. Neuron 2013, 80, 588-601. [CrossRef] [PubMed]

29. Breier, J.M.; Gassmann, K.; Kayser, R.; Stegeman, H.; De Groot, D.; Fritsche, E.; Shafer, T.J. Neural progenitor cells as models for high-throughput screens of developmental neurotoxicity: State of the science. Neurotoxicol. Teratol. 2010, 32, 4-15. [CrossRef] [PubMed]

30. Schmidt, B.Z.; Lehmann, M.; Gutbier, S.; Nembo, E.; Noel, S.; Smirnova, L.; Forsby, A.; Hescheler, J.; Avci, H.X.; Hartung, T.; et al. In vitro acute and developmental neurotoxicity screening: An overview of cellular platforms and high-throughput technical possibilities. Arch. Toxicol. 2017, 91, 1-33. [CrossRef] [PubMed]

31. Takahashi, K.; Tanabe, K.; Ohnuki, M.; Narita, M.; Ichisaka, T.; Tomoda, K.; Yamanaka, S. Induction of pluripotent stem cells from adult human fibroblasts by defined factors. Cell 2007, 131, 861-872. [CrossRef] [PubMed]

32. Ludwig, T.E.; Bergendahl, V.; Levenstein, M.E.; Yu, J.; Probasco, M.D.; Thomson, J.A. Feeder-independent culture of human embryonic stem cells. Nat. Methods 2006, 3, 637-646. [CrossRef] [PubMed]

33. Moore, J.C.; Sheldon, M.H.; Hart, R.P. Biobanking in the Era of the Stem Cell: A Technical and Operational Guide; Morgan \& Claypool Life Sciences: San Rafael, CA, USA, 2012; p. 78.

34. Goff, L.A.; Davila, J.; Swerdel, M.R.; Moore, J.C.; Cohen, R.I.; Wu, H.; Sun, Y.E.; Hart, R.P. Ago2 immunoprecipitation identifies predicted microRNAs in human embryonic stem cells and neural precursors. PLoS ONE 2009, 4, e7192. [CrossRef] [PubMed]

35. Gerrard, L.; Rodgers, L.; Cui, W. Differentiation of human embryonic stem cells to neural lineages in adherent culture by blocking bone morphogenetic protein signaling. Stem Cells 2005, 23, 1234-1241. [CrossRef] [PubMed]

36. Livak, K.J.; Schmittgen, T.D. Analysis of relative gene expression data using real-time quantitative PCR and the 2(-delta delta c(t)) method. Methods 2001, 25, 402-408. [CrossRef] [PubMed]

37. Sauvageau, M.; Goff, L.A.; Lodato, S.; Bonev, B.; Groff, A.F.; Gerhardinger, C.; Sanchez-Gomez, D.B.; Hacisuleyman, E.; Li, E.; Spence, M.; et al. Multiple knockout mouse models reveal lincRNAs are required for life and brain development. eLife 2013, 2, e01749. [CrossRef] [PubMed] 
38. Kageyama, R.; Ohtsuka, T. The Notch-Hes pathway in mammalian neural development. Cell Res. 1999, 9, 179-188. [CrossRef] [PubMed]

39. Peng, I.; Binder, L.I.; Black, M.M. Cultured neurons contain a variety of microtubule-associated proteins. Brain Res. 1985, 361, 200-211. [CrossRef]

40. Bai, J.; Ramos, R.L.; Ackman, J.B.; Thomas, A.M.; Lee, R.V.; LoTurco, J.J. RNAi reveals doublecortin is required for radial migration in rat neocortex. Nat. Neurosci. 2003, 6, 1277-1283. [CrossRef] [PubMed]

41. Buzanska, L.; Sypecka, J.; Nerini-Molteni, S.; Compagnoni, A.; Hogberg, H.T.; del Torchio, R.; Domanska-Janik, K.; Zimmer, J.; Coecke, S. A human stem cell-based model for identifying adverse effects of organic and inorganic chemicals on the developing nervous system. Stem Cells 2009, 27, 2591-2601. [CrossRef] [PubMed]

42. Kim, H.Y.; Wegner, S.H.; Van Ness, K.P.; Park, J.J.; Pacheco, S.E.; Workman, T.; Hong, S.; Griffith, W.; Faustman, E.M. Differential epigenetic effects of chlorpyrifos and arsenic in proliferating and differentiating human neural progenitor cells. Reprod. Toxicol. 2016, 65, 212-223. [CrossRef] [PubMed]

43. Zarei, M.H.; Soodi, M.; Qasemian-Lemraski, M.; Jafarzadeh, E.; Taha, M.F. Study of the chlorpyrifos neurotoxicity using neural differentiation of adipose tissue-derived stem cells. Environ. Toxicol. 2016, 31, 1510-1519. [CrossRef] [PubMed]

44. Slotkin, T.A.; Skavicus, S.; Card, J.; Levin, E.D.; Seidler, F.J. Diverse neurotoxicants target the differentiation of embryonic neural stem cells into neuronal and glial phenotypes. Toxicology 2016, 372, 42-51. [CrossRef] [PubMed]

45. Christen, V.; Rusconi, M.; Crettaz, P.; Fent, K. Developmental neurotoxicity of different pesticides in PC-12 cells in vitro. Toxicol. Appl. Pharmacol. 2017, 325, 25-36. [CrossRef] [PubMed]

46. Sindi, R.A.; Harris, W.; Arnott, G.; Flaskos, J.; Lloyd Mills, C.; Hargreaves, A.J. Chlorpyrifos- and chlorpyrifos oxon-induced neurite retraction in pre-differentiated N2a cells is associated with transient hyperphosphorylation of neurofilament heavy chain and ERK 1/2. Toxicol. Appl. Pharmacol. 2016, 308, $20-31$. [CrossRef] [PubMed]

47. Kageyama, R.; Ohtsuka, T.; Hatakeyama, J.; Ohsawa, R. Roles of bHLH genes in neural stem cell differentiation. Exp. Cell Res. 2005, 306, 343-348. [CrossRef] [PubMed]

48. Ohtsuka, T.; Ishibashi, M.; Gradwohl, G.; Nakanishi, S.; Guillemot, F.; Kageyama, R. Hes1 and Hes5 as notch effectors in mammalian neuronal differentiation. EMBO J. 1999, 18, 2196-2207. [CrossRef] [PubMed]

49. Nishimura, M.; Isaka, F.; Ishibashi, M.; Tomita, K.; Tsuda, H.; Nakanishi, S.; Kageyama, R. Structure, chromosomal locus, and promoter of mouse Hes2 Gene, a homologue of Drosophila hairy and Enhancer of split. Genomics 1998, 49, 69-75. [CrossRef] [PubMed]

50. Hatakeyama, J.; Bessho, Y.; Katoh, K.; Ookawara, S.; Fujioka, M.; Guillemot, F.; Kageyama, R. Hes genes regulate size, shape and histogenesis of the nervous system by control of the timing of neural stem cell differentiation. Development 2004, 131, 5539-5550. [CrossRef] [PubMed]

51. Lavado, A.; Oliver, G. Jagged1 is necessary for postnatal and adult neurogenesis in the dentate gyrus. Dev. Biol. 2014, 388, 11-21. [CrossRef] [PubMed]

52. Wilhelmsson, U.; Faiz, M.; de Pablo, Y.; Sjoqvist, M.; Andersson, D.; Widestrand, A.; Potokar, M.; Stenovec, M.; Smith, P.L.; Shinjyo, N.; et al. Astrocytes negatively regulate neurogenesis through the Jagged1-mediated Notch pathway. Stem Cells 2012, 30, 2320-2329. [CrossRef] [PubMed]

53. Scholl, F.G.; Scheiffele, P. Making connections: Cholinesterase-domain proteins in the CNS. Trends Neurosci. 2003, 26, 618-624. [CrossRef] [PubMed]

54. Brazzolotto, X.; Wandhammer, M.; Ronco, C.; Trovaslet, M.; Jean, L.; Lockridge, O.; Renard, P.Y.; Nachon, F. Human butyrylcholinesterase produced in insect cells: Huprine-based affinity purification and crystal structure. FEBS J. 2012, 279, 2905-2916. [CrossRef] [PubMed]

55. Bodur, E.; Layer, P.G. Counter-regulation of cholinesterases: Differential activation of PKC and ERK signaling in retinal cells through BChE knockdown. Biochimie 2011, 93, 469-476. [CrossRef] [PubMed]

(C) 2018 by the authors. Licensee MDPI, Basel, Switzerland. This article is an open access article distributed under the terms and conditions of the Creative Commons Attribution (CC BY) license (http:/ / creativecommons.org/licenses/by/4.0/). 